Interactive comment on "Deeply subducted continental fragments: I. Fracturing, dissolution-precipitation and diffusion processes recorded by garnet textures of the central Sesia Zone (Western Italian Alps)" by Francesco

\title{
Giuntoli et al.
}

Francesco Giuntoli et al.

francesco.giuntoli@plymouth.ac.uk

Received and published: 1 November 2017

Please see the attached PDF for our comments to Ortolano Referee2 
Interactive comment on Solid Earth Discuss., https://doi.org/10.5194/se-2017-87, 2017.

SED

Interactive comment 